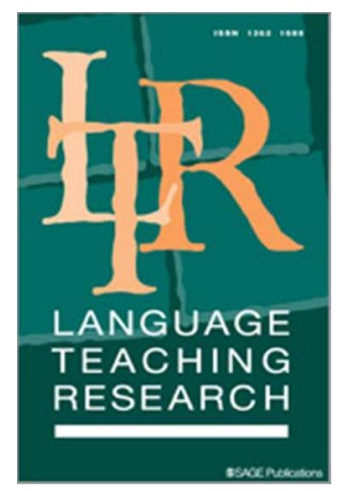

\title{
The power of sound in L2 idiom learning
}

\begin{tabular}{|c|c|}
\hline Journal: & Language Teaching Research \\
\hline Manuscript ID & LTR-15-0203.R1 \\
\hline Manuscript Type: & Full Research Article \\
\hline Keywords: & $\begin{array}{l}\text { L2 phrase learning, figurative idioms, phonological similarity, recall of } \\
\text { forms, explicit instruction }\end{array}$ \\
\hline Abstract: & $\begin{array}{l}\text { Corpus analyses of learners' dictionaries of English idioms have revealed } \\
\text { that } 11 \% \text { to } 35 \% \text { of English figurative idioms show either alliteration (miss } \\
\text { the mark) or assonance (get this show on the road), depending on the type } \\
\text { considered. Because multiword combinations, particularly idiomatic } \\
\text { expressions, present a huge challenge even for advanced learners of } \\
\text { English, elaborative techniques that help learners come to grips with this } \\
\text { part of the lexicon are welcome. In this study we investigated whether } \\
\text { phonological similarity (i.e., alliteration and assonance) facilitates the } \\
\text { delayed recall of common L2 figurative idioms which were not known at } \\
\text { pretest. In a quasi-experiment involving } 50 \text { EFL learners, one group ( } \mathrm{n}= \\
26 \text { ) learned significantly more phonologically similar (PhS) idioms than } \\
\text { nonPhS (control) idioms after a treatment designed both to raise } \\
\text { awareness of phonological similarity (PhS) and to direct attention toward } \\
\text { occurrences of it. Learners in a comparison group ( } \mathrm{n}=24 \text { ), who } \\
\text { experienced no awareness raising or attention direction, recalled more } \\
\text { nonPhS idioms. We conclude that the potential of sound repetition needs to } \\
\text { be unlocked by pedagogical interventions if learners are to reap mnemonic } \\
\text { benefits from it. }\end{array}$ \\
\hline
\end{tabular}


Abstract

Corpus analyses of learners' dictionaries of English idioms have revealed that $11 \%$ to $35 \%$ of English figurative idioms show either alliteration (miss the mark) or assonance (get this show on the road), depending on the type considered. Because multiword combinations, particularly idiomatic expressions, present a huge challenge even for advanced learners of English, elaborative techniques that help learners come to grips with this part of the lexicon are welcome. In this study we investigated whether phonological similarity (i.e., alliteration and assonance) facilitates the delayed recall of common L2 figurative idioms which were not known at pretest. In a quasi-experiment involving 50 EFL learners, one group $(n=26)$ learned significantly more phonologically similar $(\mathrm{PhS})$ idioms than nonPhS (control) idioms after a treatment designed both to raise awareness of phonological similarity $(\mathrm{PhS})$ and to direct attention toward occurrences of it. Learners in a comparison group $(n=24)$, who experienced no awareness raising or attention direction, recalled more non $\mathrm{PhS}$ idioms. We conclude that the potential of sound repetition needs to be unlocked by pedagogical interventions if learners are to reap mnemonic benefits from it.

\section{Keywords}

L2 phrase learning, figurative idioms, phonological similarity, recall of forms, explicit instruction 


\section{Introduction}

In order to attain a high level of proficiency in a foreign language learners need to familiarize themselves with very many formulaic sequences, which is a challenging undertaking for most post-childhood learners (Li and Schmitt 2009; Qi and Ding 2011). One type of L2 formulaic sequence that is especially troublesome is that of idioms. Various means have been suggested whereby teachers and materials writers might help learners acquire L2 idioms with greater success (for reviews see Author 2009; 2012). One proposal, directed particularly at the learning of forms, is to raise learners' awareness of the prevalence of sound repetition in English idioms. This proposal is based on two assumptions. The first is that given appropriate pedagogical intervention certain patterns of sound repetition, or phonological similarity $(\mathrm{PhS})$, render L2 phrasal expressions relatively memorable. The second is that these patterns of $\mathrm{PhS}$ are sufficiently common in the L2 phrasal lexicon for the first assumption to be of interest. In this article both assumptions will be addressed.

Idioms are so multifarious that it is common for researchers to regard the category as fuzzy (e.g., Nunberg, Sag, and Wasow 1994; Zyzkik 2011). Although our proposals are not necessarily limited to any one type of idiom, in this article we focus on so-called figurative idioms - that is, relatively fixed, typically informal conventional expressions whose meanings arise at least in part from a trope such as metaphor, metonymy, hyperbole, and/or irony (Gibbs 1994; Nunberg et al. 1994). In adopting this focus we follow other researchers of L2 idiom learning such as Author (2007); Grant, (2007), and Zyzik (2011).

\section{Sound repetition in English phraseology: alliteration and assonance}

The current study is concerned with two patterns of intra-phrase $\mathrm{PhS}$-alliteration and assonance. We define alliteration as the occurrence of the same consonant onset in two or 
more content words within a phrase (e.g., miss the mark) and assonance as the repetition of a vowel in a prominent syllable of two or more content words within a phrase, as in jump the gun (basic assonance), a quick fix (near rhyme), go with the flow (clipped rhyme), and make a mistake (rhyme, which is regarded here as a special case of assonance). A question we first need to address is how common alliteration and assonance are in English idioms. Extending a previously reported study (Author 2014a), we searched through a learner's dictionary of English idioms (Parkinson 2006), examining all defined expressions which include at least two content words in addition to any verb or verbs. Of 2906 such expressions (e.g., Let the cat out of the bag, the name of the game, a hornet's nest), 232 (8\%) were identified as alliterative and $392(13.5 \%)$ as assonant. Altogether, about 21\% showed alliteration and/or assonance. Of the 197 so-called 'binomial idioms' (e.g., high and dry) not signalled as “oldfashioned", about 38\% show alliteration and/or assonance. Of 71 'as idioms' (e.g., as good as gold), about $35 \%$ alliterate and/or assonate. We also examined alternate five page blocks throughout Parkinson (2006), taking note of all defined noun phrases of the structure (DETERMINER or POSSESSIVE PRONOUN) + QUALIFIER Or NOUN + NOUN (e.g., top dog, hobby horse). Of 221 such expressions $28 \%$ show either alliteration or assonance. Other counts (through different learner's English idioms dictionaries) focusing only on alliteration but covering all defined expressions have found its incidence to be 13\% (Author 2009, p. 114) and $17 \%$ (Boers and Stengers 2008). If alliteration and/or assonance have a large enough positive mnemonic effect on learners' ability to remember L2 phrases, occurrence rates such as those just mentioned may mean that these patterns of $\mathrm{PhS}$ can facilitate L2 idiom learning to some useful degree. We now briefly survey evidence that relations of $\mathrm{PhS}$ do influence lexical recall.

\section{Experimental evidence for positive effects of phonological similarity on lexical recall}


In recent decades most experimental investigations of the mental lexicon have taken place within a connectionist framework in which it is expected, for instance, that activation of a word in memory (the activation being brought about, for example, by the mention of a particular topic) may spread to other words. That is, these other words are also activated, whereby they too become more available for processing and for production. Within a connectionist framework it is expected that the activation of one word by another is especially likely to take place if the two words are semantically related and/or phonologically similar (e.g., Gupta and MacWhinney 1997; Luce, Goldinger, Auer, and Vitevitch 2000; Storkel and Morrisette 2002). The connectionist view accounts well for the results of a vast number of investigations of $\mathrm{PhS}$ effects on the accessibility of words in memory. Some twenty years ago Rubin (1995) noted that hundreds of studies had been carried out to investigate $\mathrm{PhS}$ effects on participants' ability to learn lists of 'paired associates', that is, pairs of items-typically short L1 words or invented L1-like nonwords (see Rubin, 1995, for an overview). In these studies the item pairings are stipulated by the researchers. Typically, participants go through several cycles of 'practicing' (i.e., trying to memorize) the pairings and then being tested on them. A strong finding is that when participants are asked to recall practiced word-pairs in any order they like, pairs that show PhS are learned faster and recalled better than nonPhS pairs. This holds true for rhyme (e.g., Bower and Bolton 1969; Nelson and Garland 1969), for alliteration+assonance (e.g., $\underline{\text { hat }}$ - $\underline{\text { ham }}$ ) (Bower and Bolton 1969; Nelson and Garland 1969), and for alliteration and assonance separately (Nelson and Garland 1969).

A second extensive subliterature is concerned with learning lists of unpaired words or nonwords. When participants are asked to recall these items in any order, they succeed better with ones that show PhS, a trend of results which holds for alliteration and rhyme (Gupta, 
Lipinski, and Actunc 2005) as well as basic assonance (Watkins, Watkins, and Crowder 1974).

Positive effects of $\mathrm{PhS}$ have also been observed in studies of implicit priming, where observed response times are shorter when primes and response words alliterate than when they do not, with response times being shorter still when primes and response words both alliterate and assonate (for a summary see Levelt 1999).

An additional relevant stream of research concerns the extent to which relations of $\mathrm{PhS}$ make primarily oral poetic texts relatively easy to recall. As might be expected, research has identified rhyme and alliteration as factors that facilitate ability to recall small-scale passages of song lyrics and traditional counting out rhymes: Provided that one of a pair or set of PhS words is recalled, recall of the other(s) is made more likely (Rubin 1995).

We know of no studies in any of the research streams touched on above which directly address $\mathrm{PhS}$ effects on the recollectability of conventionalized phrases in L1 or L2. One probable reason for this research gap is the extreme difficulty even in a laboratory setting of controlling for nuisance semantic variables when the stimulus expressions are real phrases: After all, achieving approximate control is hard enough in the case of real single words. However, in practice-oriented L2 research a more exploratory approach may be called for than is normal in psycholinguistics. Accordingly, there have been a number of (quasi)experimental paired-design studies of the extent to which alliteration and assonance help upper-intermediate and advanced learners recall or recognize short L2 English phrasal expressions (usually collocations such as full force) as compared to non-phonologically similar (nonPhS) expressions (e.g., full speed) (Author 2014a; Author 2012, 2014b/c; Author 2008a/b). In general, a positive effect ranging from large to medium-small has been found following treatments that included brief awareness raising about alliteration or assonance and/or an intervention to direct participants' attention to the phonological form of the 
stimulus expressions. Only small positive effects or even negative ones (Author 2014c) have been observed in the absence of such pedagogical interventions. Generally, though, the recall advantage shown by phonologically similar $(\mathrm{PhS})$ expressions has been found to dissipate with time. In some cases no effect was detected in posttests administered after a delay of from 24 hours to one week. It should be noted however that these studies have focused not on participants' learning of previously unknown expressions but on their ability to recall familiar expressions that happened to be encountered on a particular occasion, that is, during the experimental treatment. Thus, these studies are much more likely to have probed 'episodic memory' than 'semantic memory' (cf., Tulving 1972; Nadel and Hardt 2011). To elaborate, episodic memory preserves a link between items of information and the context(s) in which the items were encountered and encoded. Episodic memory would be drawn on in following an instruction like this, 'Please write down, from memory, as many as you can of the twoword phrases that you sorted and then dictated to each other at the beginning of class last Tuesday'. Semantic memory, which tends to be more durable and which underpins most everyday language use, does not preserve the link between something that is known (e.g., a phrase) and the occasion when it was learned (Tulving 1972; Nadel and Hardt 2011). We know of five studies which have investigated the storage and relative accessibility in semantic memory of previously unknown phrasal expressions (both $\mathrm{PhS}$ and nonPhS), including figurative idioms (Author 2005, experiments 1-3, Author 2014d, and Author 2008a, experiment 3). That is, the tests of recall used in these studies did not require participants specifically to remember whether the targeted expressions had or had not been been encountered on a particular list or in another stipulated context that was encountered or experienced at a particular time and place. In each of these five studies alliteration was found to have facilitated participants' ability to recall the forms of phrasal expressions that the participants either definitely did not know or else were unlikely to have known before the 
study began. However, these studies were either very small in scale or they involved analysis of data originally collected for a different purpose than that of investigating $\mathrm{PhS}$ effects on L2 phrase learning. Moreover, none of these five studies explicitly included assonance in its focus. For these reasons additional experimental investigation seemed to be in order.

\section{The research questions}

Our aim in this experiment was to investigate:

(1) whether, with respect to recollectability from semantic memory, previously unfamiliar $\mathrm{PhS}$ idioms have an inherent advantage over previously unfamiliar nonPhS idioms; if not, (2) whether an experimental treatment including brief awareness raising about $\mathrm{PhS}$ patterns in idioms and a simple attention direction task leads to higher recall rates of $\mathrm{PhS}$ idioms than when participants are not made aware of the sound patterns in the target idioms; and if so,

(3) whether this outcome occurs at the expense of recall of the nonPhS idioms in the set of idioms to be learned.

These research questions were operationalized by comparing the number of idioms participants could not produce at pretest with the number that they could produce in posttest immediately following the study session and in a delayed posttest administered a week later. In the experimental condition the treatment included brief awareness raising about patterns of $\mathrm{PhS}$ in idioms, following which participants were set a marking task intended to direct their attention to instances of $\mathrm{PhS}$ among the set of stimulus idioms. This condition is hereafter referred to as the $\mathrm{AD}$ condition and the group that experienced it, as the $\mathrm{AD}$ group. In the comparison condition, the treatment consisted simply in the participants being asked to study the targeted $\mathrm{PhS}$ and nonPhS idioms according to their own preferred personal learning strategies. This condition is hereafter referred to as the noAD condition and the group that 
experienced it as the noAD group. Both an immediate and a delayed posttest were administered to measure learning gains.

\section{Method}

\section{Participants}

The 50 participants who completed all stages of the experiment were Dutch-speaking students aged 19 to 21 majoring in English and an additional foreign language at the Department of Translation, Interpreting and Communication of Ghent University, Belgium. They formed two intact classes of respectively 26 and 24 students and their level of proficiency in English was estimated as B2 according to the Common European Framework of Reference for Languages (CEF), which corresponds to an IELTS score of 5 to 6.5. Each class was assigned to one of the treatments $\left(n_{\mathrm{AD}}=26 ; n_{\mathrm{noAD}}=24\right)$.

\section{Materials}

The expressions targeted in this experiment were 26 L2 English idioms drawn from two learner's dictionaries, as detailed further below. Of these 26 stimulus idioms, 13 show $\mathrm{PhS}$ (as shortly to be described) and 13 'control' idioms do not (see Table 1). With the exception of the delayed post-test, on every occasion that the students encountered the target idioms-always in a different random order-there were two filler idioms before the block of target idioms and another two at the end. This was to mitigate primacy and recency effects. These fillers (turn back the clock, read between the lines, reach for the stars, bridge the gap) were never presented in the same order twice. Of the $\mathrm{PhS}$ idioms, six show alliteration but not

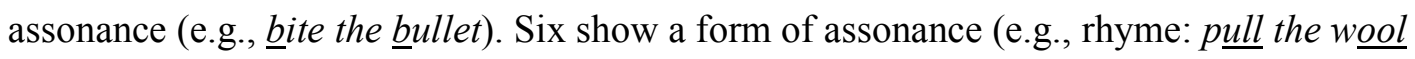
over someone's eyes; near rhyme: cook the books; and basic assonance: jump the gunn). And one shows alliteration and assonance (ive off the fat of the land). 
Attempts were made to control for variables that are known to influence retention but which are extraneous to the variables of interest, that is, the presence or absence of $\mathrm{PhS}$ and of awareness raising followed attention direction. Table 2 summarizes how the two sets of idioms compare in terms of length, frequency, and imageability of meaning. The slightly lesser average length of the nonPhS idioms was expected to favour their recall very slightly. The considerably greater average whole phrase and word frequencies of the $\mathrm{PhS}$ idioms might be thought likely to favour their recall. However, it has been found that the amount of attention paid to a lexical item may correlate negatively with familiarity and, therefore, with frequency (cf., Tulving and Kroll 1995). Indeed, as will be seen, item frequencies appear to have played a negligible role in the outcomes we observed. We were much more concerned about the variable 'imageability of meaning' (i.e., the degree to which a given idiom conveys a sensori-motoric image) since imageability has long been known to be a powerful facilitator of lexical recall (Paivio, Yuille, and Madigan 1968). To make the experiment a good test of whether $\mathrm{PhS}$ can have a positive mnemonic effect, it was essential that the imageability of the $\mathrm{PhS}$ idioms be equal to or even (to be on the safe side) somewhat less than that of the nonPhS idioms. As we know of no published imagery ratings for idioms, we showed $33 \mathrm{~L} 1$ undergraduate Dutch informants a shortlist of 32 candidate idioms and collected from them ratings of these idioms on a 7 point scale. Specifically, the informants were each given a copy of the study sheet used in the experiment, but with 32 idioms rather than the eventual smaller number. It was on this sheet that the informants wrote their imageability ratings. They were also given an instruction sheet reading as follows:

\footnotetext{
"Could you give your impression of the imageability of each of the following idioms? Specifically, how much does it suggest to you an image that is visual or which involves movement or physical contact. Please give a separate rating for each idiom
} 
on a scale of 1 (difficult to form an image) to 9 (extremely easy to form an image).

(No half scores, please).”

Informants were asked to consider not only the idioms themselves but also the glosses and the examples of use shown on the study sheet. To minimize overall variation in the amount of attention paid to individual idioms, each informant was randomly assigned a different idiom as a starting point on the study sheet. It turned out that the 16 candidate $\mathrm{PhS}$ idioms were rated as more imageable on average than the 16 nonPhS ones. The desired balance was achieved by discarding the three highest rated $\mathrm{PhS}$ idioms and the three lowest rated nonPhS ones. Table 1 shows the final list of 26 idioms.

Table 1 about here.

Table 2 about here

The targeted idioms were drawn from the Oxford Idioms Dictionary for Learners of English (Parkinson 2006) apart from two drawn from the online version of the Cambridge Advanced Learner's Dictionary and Thesaurus (CALDT) (http://dictionary.cambridge.org/dictionary/british/). The glosses and examples given on the tests and on the study-sheet that participants consulted during the study phase were drawn from Parkinson (2006) except where the definition or example in CALDT was clearly superior. For example, Parkinson defines miss the mark as "not succeed in achieving or guessing sth". Because this seemed vague to us, we chose the gloss in CALDT: "fail to achieve the result that was intended". For this idiom we also used the example given by CALDT, since Parkinson does not provide one.

Procedure 
In a pen and paper pretest administered by one of the authors, participants were asked to complete the 26 target idioms along with four fillers. Each of the 30 test items had the same format: A single noun was gapped in each targeted idiom, except for that noun's first letter. With one exception, the gapped word was always the word following the article the (e.g., REACH FOR THE S__ ). The exception was the idiom HAVE BIGGER F_ TO FRY, which includes no article. Participants were asked to write their name on their pre-test sheet before handing it in.

Next, a study booklet was handed out. It consisted of a section for each idiom (including the four fillers). Each section presented (a) the complete canonical form of a targeted idiom, (b) a definition for it taken from a learner's dictionary, and (c) an illustration of usage also taken from a learners' dictionary, for example:

STAY THE COURSE. Continue doing sth until it has finished or been completed, even though it is difficult. "Very few of the trainees have stayed the course."

MISS THE MARK. Fail to achieve the result that was intended. "Her speech missed the mark and failed to generate the public support she had been hoping for."

In the noAD condition participants were asked to study the idioms on these sheets. No mention was made of sound repetition and students were given no task designed to cause them to pay more attention to phonological form than they would if left to their own devices. In the $\mathrm{AD}$ condition the researcher first briefly outlined a common rhetorical function of idioms-that of summing up one's attitude to an event or situation (McCarthy 1998, pp. 131149)-and proposed that sound repetition, as in tear one's hair [out], might have rhetorical impact over and above any impact of the idiom's meaning alone. The participants were then 
asked to study the idioms and to mark the keywords in the idiom that share a sound with the boxed content word. The researcher recommended to participants that they repeat the target idioms subvocally in order to become more aware of any sound repetition. For both groups, time was called after about 15 minutes and these sheets were collected.

In both conditions the participants were told they would afterwards be tested on their knowledge of the form of each of the idioms. The first posttest, which followed immediately, consisted of test items in which all the content words of the idiom were gapped except for the first letter. The appropriate gloss was repeated from the study-sheet, but not the example of usage.

$\mathrm{H} \longrightarrow \mathrm{B} \longrightarrow \mathrm{F}$ important, interesting, or useful things to do.

When everyone had finished the test (after approximately ten minutes) the test sheets were collected, and the instructor moved on to unrelated matters. A week later, the unannounced delayed post-test was given. This test had the same format as the pretest; that is, one content word in the targeted idiom was gapped except for its first letter, and after the idiom there was a gloss. As this was the final test to be given, no fillers were included. When everyone had finished the test (after approximately seven minutes) the test sheets were collected.

\section{Design, data analysis, and results}

In our design the outcome variable, recall of form, was measured by the raw scores on three tests: (1) a pretest of ability to produce targeted idioms when given a first letter cue for one omitted content word; (2) an immediate posttest where multiple content words were omitted except for their first letters; and (3) a one-week delayed posttest that was essentially identical to the pretest. The independent variable 'presence / absence of awareness raising and 
attention direction' defined the experimental (AD) and the comparison (noAD) conditions. The other independent variable was 'presence / absence of $\mathrm{PhS}$ ', which was nested under 'Idioms'. Each participant was exposed to and was tested on each of the 26 targeted idioms, meaning that for each participant each test produced two key measures-specifically, one aggregated raw score (out of a possible 13) for the $\mathrm{PhS}$ idioms and another aggregated raw score (out of 13) for the nonPhS idioms. To measure learning from the prettest to a posttest, each participant's relevant aggregated raw scores were converted into 'gain scores', which were derived from the raw scores according to the standard formula: GAIN SCORE $=$ RAW POSTTEST SCORE - RAW PRETEST SCORE. On each posttest each participant had one aggregated gain score for the $\mathrm{PhS}$ idioms and one for the nonPhS idioms. But it was only the pretestdelayed posttest aggregated gain scores that were subjected to inferential statistical analysis. Finally, for descriptive purposes, each participant's aggregated $\mathrm{PhS}$ and nonPhS pretest to delayed posttest gain scores were converted into a single 'gain difference score', which could be positive, negative, or zero, according to the formula: GAIN DIFFERENCE SCORE $=$ GAIN

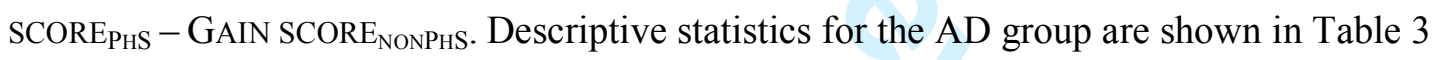
and those for the noAD group are shown in Table 4. Note in particular that while the mean pretest scores of the $\mathrm{AD}$ and noAD groups are similar, the $\mathrm{AD}$ group's total of pretest to delayed posttest gain scores is higher than that of the noAD group (306 vs 268) and that the AD group's gain score subtotal for the $\mathrm{PhS}$ idioms is markedly higher than that of the noAD group (169 vs 123) while the two groups' subtotals for the nonPhS idioms are much less different (137 vs 145).

Tables 3 and 4 give details for the immediate posttest mainly for completeness: Scores from this test were not subjected to inferential analysis because ephemeral learning was not the prime concern. However, the pretest to immediate posttest and pretest to delayed 
posttest learning trends were basically the same. This is shown by Figures 1 and 2, each of which includes one ladder plot for each of the four combinations of $+/$ - attention direction (AD) and +/-PhS. In each ladder plot, a diagonal line extending from a pretest score to a delayed posttest score represents the learning trajectory of one participant. (There may be some superpositioning of lines despite random jittering of lines.) In other words, each ladder plot is a profile of gains and each profile in Figure 1 is similar to the corresponding profile in Figure 2. ${ }^{1}$

[Table 3 about here]

[Table 4 about here]

[Figure 1 about here beneath its caption]

[Figure 2 about here beneath its caption]

As the Anderson-Darling test of distributional normality $(\alpha=.20)$ red-flagged a number of the pertinent score sets, we tested the difference between participants' $\mathrm{PhS}$ and nonPhS pretest to delayed posttest aggregated gain scores using Rand Wilcox's (2012, pp. 406-407) 'yuend' R function which runs a robust version of the paired $t$-test. ${ }^{2}$ Key results are as follows, where all tests were two-sided and $\alpha=.05$.

AD group: $M D=1.23, t=2.14_{(25)}, p=.042 .^{3}$ The estimated effect size is: $d=0.59$, $95 \% \mathrm{CI}[0.03,1.14]$. The latter interval ranges from a trivial positive effect to one that is large. However, the point estimate $(d=0.59)$, which is indicative of a strongish medium effect, is about seven times more likely than the value at either limit (Cumming, 2012: 99100) and is well above average for effects observed in educational research generally (Grissom and Kim, 2012: 127-130). 
noAD group: $M D=-0.92, t=-1.78_{(23)}, p=.088, d=-0.51[-1.09,0.07] .{ }^{4}$ The $d$ value here is consistent with an effect of medium size, albeit in the opposite direction to that seen in the AD condition.

Finally, we have not yet mentioned how accurately participants in the AD condition marked the $\mathrm{PhS}$ idioms as such or on how well they refrained from marking nonPhS idioms. With 26 participants and 13 idioms in each of the two sets, 338 is the maximum possible number of correct marks. The number of marks given the $\mathrm{PhS}$ idioms was $236(69 \%$ of the total possible). NonPhS idioms were wrongly marked as $\mathrm{PhS} 27$ times ( $8 \%$ of the maximum possible).

\section{Discussion}

Let us now consider the three research questions (RQs) in turn. Regarding RQ 1, our data is not consistent with $\mathrm{PhS}$ idioms being inherently more memorable since the noAD group remembered those idioms markedly less well than they did the nonPhS idioms. RQ 2 asks whether $\mathrm{PhS}$ idioms can be rendered extra-memorable for learners who experience some awareness raising about patterns of $\mathrm{PhS}$ and also a task that induces them to look out for instances of $\mathrm{PhS}$ in idioms that they encounter. Our results suggest that the answer to this question is 'Yes'. (In Figure 2, the ladder plot for the AD group, top right, runs higher than the plot for any other group.) Finally, RQ 3 asks whether the awareness raising and attention direction experienced by the AD group detracted from their learning of the nonPhS idioms. Because we did not form the $\mathrm{AD}$ and noAD groups by random assignment of participants, there is a less than optimal basis for direct comparisons of one group with the other. However, the two groups of participants were alike in many respects and, as can be seen in Table 3 and 4, their mean pretest scores for both types of idiom are very similar, as are their 
gains on the nonPhs idioms ( $137_{\mathrm{AD}}$ vs $\left.145_{\mathrm{noAD}}\right)$, where the disparity is far less than on the $\mathrm{PhS}$ idioms $\left(169_{\mathrm{AD}} \mathrm{vs} 123_{\mathrm{noAD}}\right)$. True, the noAD group's mean pretest to delayed posttest gain score for the nonPhS idioms is $5.8 \%$ higher than that of the AD participants. But let's refer to the two plots in the left column of Figure 2: They show very similar gain profiles for the nonPhS for both learning conditions; and both profiles are consistent with pretty good learning of the nonPhS idioms over the period of the experiment. To approach RQ3 in a different way, recall that it was the AD group that made the greatest total learning gains (i.e., for $\mathrm{PhS}$ and nonPhS idioms together). That is, for the $\mathrm{AD}$ group there are 306 gain scores vs 268 for the noAD group, for a superiority of $114 \%\left(306_{\mathrm{AD}} / 268_{\mathrm{noAD}}=1.14\right)$. All in all, there is no evidence that the experimental treatment engendered a trade-off effect, let alone one large enough to be substantively important.

It may be asked why the noAD participants remembered the nonPhS idioms so much better than the $\mathrm{PhS}$ idioms, which was a result that we did not expect. Both Figure 1 and in Figure 2 it can be seen that the lower-right plot (noAD, $+\mathrm{PhS})$ is different from all the others. Looking at Figure 2 we see three rather flat diagonal lines at the bottom of the score range. These indicate that three of the noAD participants who had very low pretest scores made especially poor gains on $\mathrm{PhS}$ idioms at the delayed posttest: There is even one case of decline. If the scores of these three noAD group participants are discarded, the point estimate of $d$ for the noAD condition leaps toward zero $(-0.51 \rightarrow-0.24)$. We cannot, however, pinpoint a reason for the overall inferior memorability of the $\mathrm{PhS}$ idioms in the noAD condition. It may or may not be the case that some of the PhS idioms just happen to be ones that learners, perhaps lower proficiency learners in particular, find hard to remember when there has been no prior awareness raising and direction of attention. 
Further above we referred to Table 2, in which it can be seen that, compared to the nonPhS idioms, the PhS idioms have greater median frequency values for whole idioms, all content words, and words intended as responses in the pretest and delayed posttest (Table 2). To get an idea of the roles of these three nuisance variables in our study we checked the association between pretest to delayed posttest aggregated gain scores and each of these measures of frequency. Like most sets of frequencies of lexical items, the ones at issue here show pronounced positive skew. We therefore followed normal practice for frequency data and reduced the skew in each data set by applying the logarithmic transformation (Baayen 2006). When we applied the Anderson-Darling normality test to the transformed frequency data, the appearance of distributional nonnormality persisted. Therefore, to calculate correlations between the transformed frequencies and the gain scores associated with each of the 26 targeted idioms we used the robust percentage bend correlation $\left(r_{\mathrm{pb}}\right)$, rather than Pearson's $r$ ( or $r_{\mathrm{S}}$ ), since $r_{\mathrm{pb}}$ closely tracks $r$ under normality but tends to give a truer (potentially far truer) estimate of the population correlation under nonnormality (Wilcox 2005). We then squared each value of $r_{\mathrm{pb}}$ in order to obtain an analog of $r^{2}$, the common measure of explanatory power (or variance explained). The results are: whole idiom frequency, $r_{\mathrm{pb}}=.065$ and ${r_{\mathrm{pb}}}^{2}=.004 ;$ logged mean content word frequency: $r_{\mathrm{pb}}=.093$ and $r_{\mathrm{pb}}{ }^{2}$ $=.009 ;$ and logged response word frequency: $r_{\mathrm{pb}}=-.046$ and $r_{\mathrm{pb}}{ }^{2}=.002$. These values of $r_{\mathrm{pb}}{ }^{2}$ are indicative of very small or negligible effects. Moreover, the underlying values of $r_{\mathrm{pb}}$ do not all have the same sign. It seems rather unlikely then that the greater average frequency of the $\mathrm{PhS}$ idioms played a telling role in the learning advantage shown by the $\mathrm{PhS}$ idioms. This is in line with the finding already referred to that people are likely to pay less attention to familiar phenomena than to phenomena which are unfamiliar (Tulving and Kroll 1995). The means by which the variables of idiom length and imageability were controlled for have already been described. 
Finally, in this article so far we have looked at scores matched to participants. But such scores can also be matched to language items (idioms in the present case). When this is done, each idiom is matched to one aggregated gain score that represents the number of students who learned the idiom between the pretest and the delayed posttest. Since there were two kinds of idioms in the experiment, this way of organizing the gain scores puts them in two independent sets, one set consists of the 13 gain scores for the $\mathrm{PhS}$ idioms and the other consists of the 13 gain scores for the nonPhS idioms. Because this alternative design is strictly between-items and because the effective sample size is now half what it is in the perparticipants format (i.e. 13 instead of 26), the statistical power that can now be brought to bear is greatly reduced. To elaborate, this alternate design affords a reasonable chance (i.e., $80 \%$ ) of detecting a truly existing effect at $p \leq .05$ only if this effect equates to $d 1.15$, nearly double our highest estimate of $d \approx 0.60 .^{5}$ Although in L2 research the by-idioms perspective is rarely taken into account along with the by-participants perspective (unlike psycholinguistic research), this alternative perspective should not be ignored since it codetermines the extent to which particular experimental findings are generalizable to different learners and to different idioms. ${ }^{6}$ Because inspection of the relevant by-idiom data indicated that the assumptions of distributional normality and equal variances cannot in all cases be taken for granted, these data were analyzed using an independent samples bootstrap Welch's $t$-test based on the means, with 10000 bootstrap replications for each test (Wilcox 2012, 338$343) .^{7}$ The key statistics for the $\mathrm{AD}$ group are: $M D=2.46, t=1.35, p=.188, d=0.50[-0.30$, 1.30]. ${ }^{8}$ If we refer back to the corresponding results from the by-participants analysis, we see that although the $p$ value here is over four times as large, the observed effect size can still be termed 'medium'. The statistics for the noAD group are: $M D=-1.54, t=-0.88, p=.383, d=$ $-0.33[-1.12,0.46]$. Here too, compared to the corresponding by-participants analysis, the $p$ 
value is much higher while the observed effect size has remained about the same (i.e., smallish).

\section{Conclusion}

On the delayed posttest, participants in the $\mathrm{AD}$ condition recalled more $\mathrm{PhS}$ idioms than nonPhS idioms. In the noAD condition the direction of the trend was reversed even though the stimulus idioms remained the same. The cause of this reversal is likely to have been the absence from the noAD condition of a pedagogical intervention focusing on phonological similarity. The fact that the nonPhS idioms were better recalled than the $\mathrm{PhS}$ idioms in the noAD condition, where participants were left to study the stimulus idioms any way they wanted, makes it all the more plausible that the outcome in the AD condition is directly attributable to the pedagogical intervention. All in all, our findings are very much at odds with any possibility that alliteration and assonance may have a practically significant mnemonic effect in the absence of a pedagogical intervention such as that seen in the AD condition. There remains our third research question, that of whether a pedagogical focus on alliteration and assonance may adversely affect the learning of idioms that show no such pattern of sound repetition. We found no evidence of such a trade-off effect. A key fact in this regard is that when pretest to delayed posttest gain scores for both types of idiom were counted together it was found that the $\mathrm{AD}$ group made the greater overall gain.

In the results section above we mentioned that scores can be averaged both across participants and across idioms. We mentioned too that the best basis for generalization from the findings of a study such as ours comes from a statistical analysis that takes both of these perspectives into account. Although we have given results of an analysis from each perspective, both of our analyses are rather traditional. Moreover, the results of the by-idioms analysis are less strong than those of the by-participants analysis. Our results, therefore, are in 
particular need of replication, not just with new participants but also with new idioms. Still, our results chime with those of other studies indicating that it can be worthwhile for teachers to take a small amount of extra time in class to raise learners' awareness of patterns of sound repetition in targeted idioms and perhaps also to stage relevant attention direction exercises (e.g., Author, 2005; Author, 2014d).

Finally, a question that our study has not addressed is, 'Which is likely to have the greater positive effect on memory for form: awareness raising along with attention direction or just awareness raising?' Also not addressed, or at least not directly, is the question of whether or for how long afterwards learners will autonomously profit from in-class awareness raising and attention direction with respect to sound repetition in idioms. Depending on what might be found out in this regard, it could be fruitful to carry out pairwise comparisons of the effectiveness of some of the techniques of awareness raising and attention direction that have been suggested in teachers' resource books (e.g., Author 2008c). Suppose, for instance, that a class of students propose a list of L2 idioms that they would like to learn. Among other things, the teacher could ask the learners to form pairs or threes and sort the idioms into four groups-idioms that include alliteration, ones that include assonance (including rhyme), ones that include both, and ones that include neither-and following this the teacher could lead a plenary discussion of the groupings. In an alternative exercise, the class divides into A-B pairs; each A student gets a handout showing half the targeted expressions, with each idiom in a short, representative context; each B student gets a handout showing the other half of the expressions, each in a short context; on each handout the loci of repeated sounds have already been highlighted (e.g., underlined) by the teacher; students A and B dictate their phrases to each other; they then check each other's writing and add in the highlighting of the sound repetitions; to finish, they discuss the sound repetitions and consult 
the teacher if they have any doubts. An experiment that took into consideration any difference in running time between two targeted exercise types could compare their effectiveness as means of promoting productive knowledge of targeted expressions.

\section{Notes}

1. In each of these figures there are different orthographic versions of the labels pre and post (e.g., Pre and pre). If this were not so, the software would have confused the data that these labels refer to.

2. ' $R$ ' refers to the statistical freeware (http://www.r-project.org/) (R Core Team, 2015).

3. To check this result we conducted an even more robust version of this test using the $10 \%$ trimmed mean instead of the trimmed mean, finding: $p=.036$.

4. For all paired measures, calculation of Cohen's $d$ (using pooled SDs) were based on the $t$-statistic from the robust paired $t$-test, two-sided. A more conservative method (Dunlap, Cortina, Vaslow, and Burke 1996), yields slightly lower values, i.e., $d=0.53$ instead of 0.59 (AD group) and -0.38 instead of -0.51 (noAD group).

5. Wuensch (2009) explains very clearly how to explore this kind of issue using G*Power (http://www.gpower.hhu.de/en.html), statistical freeware developed by Faul, Erdfelder, Lang, and Buchner (2007).

6. Baguley (2012, pp. 725-730) gives a good account of the issues here; see also Baayen (2006, Chapter 7.)

7. Welch's $t$-test, the default in $\mathrm{R}$, does not assume that variances are equal.

8. The same bootstrap based on the $10 \%$ trimmed mean found $p=.165$. Incidentally, bootstraps do not involve degrees of freedom. 


\section{References}

Author (2005)

Author (2006)

Author (2008a)

Author (2008b)

Author (2008c)

Author (2009)

Author (2012)

Author (2014a)

Author (2014b)

Author (2014c)

Author (2014d)

Author (2014e)

Baayen, R. (2006). Analyzing Linguistic Data. Cambridge, UK: Cambridge University Press.

Baguley, T. (2012). Serious stats: A guide to advanced statistics for the behavioral sciences. Basingstoke, UK: Palgrave Macmillan.

Boers, F., \& Stengers, H. (2008). A quantitative comparison of the English and Spanish repertoires of figurative idioms. In F. Boers \& S. Lindstromberg (Eds.), Cognitive Linguistic Approaches to Teaching Vocabulary and Phraseology (pp. 355-374). Berlin, Germany: Mouton Degruyter 
Bower, G., \& Bolton, L. (1969). Why are rhymes easy to learn? Journal of Experimental Psychology, 82, 453-461.

Cambridge Advanced Learner's Dictionary and Thesaurus. No date. Cambridge, UK: Cambridge University Press. Retrieved from http://dictionary.cambridge.org/dictionary/british/

Cohen, J. (1988). Statistical Power Analysis for the Behavioral Sciences (2nd ed.). London, UK: Erlbaum.

Cumming, G. (2011). ESCI Meta-analysis. Exploratory Software for Confidence Intervals. Retrieved from http://www.latrobe.edu.au/psy/documents/ESCI-readme.pdf

Cumming, G. (2012). Understanding the New Statistics: Effect Sizes, Confidence Intervals, and Meta-analysis. New York, NY: Routledge.

Davies, M. (2014). The Corpus of Contemporary American English. Retrieved from http://www.americancorpus.org

Dunlap, W., Cortina, J., Vaslow, J., \& Burke, M. (1996). Meta-analysis of experiments with matched groups or repeated measures designs. Psychological Methods, 1, 170-177.

Faul, F., Erdfelder, E., Lang, A.-G., \& Buchner, A. (2007). G*Power 3: A flexible statistical power analysis program for the social, behavioral, and biomedical sciences. Behavior Research Methods, 39, 175-191.

Gibbs, R. W. (1994). The Poetics of Mind: Figurative Thought, Language and Understanding. Cambridge, UK: Cambridge University Press.

Grant, L. (2007). In a manner of speaking: Assessing frequent spoken figurative idioms to assist ESL/EFL teachers. System, 35, 169-181. 
Gries S. (2011). Phonological similarity in multi-word symbolic units. Cognitive Linguistics, 22, 491-510.

Grissom, R., \& Kim, J. (2012). Effect Sizes for Research: Univariate and Multivariate Applications (2nd ed.). New York, NY: Routledge.

Gupta, P., \& MacWhinney, B. (1997). Vocabulary acquisition and verbal short-term memory: Computational and neural bases. Brain and Language, 59, 267-333.

Gupta, P., Lipinski, J., \& Aktunc, E. (2005). Reexamining the phonological similarity effect in immediate serial recall: The roles of type of similarity, category cuing, and item recall. Memory and Cognition, 33, 1001-1016.

Herrera, H., \& White, M. (2010). Canonicity and variation in idiomatic expressions: evidence from business press headline. In S. De Knop, F. Boers, \& A. De Rycker (Eds.), Fostering Language Teaching Efficiency through Cognitive Linguistics (pp. 1677-187). Berlin, Germany: Mouton de Gruyter.

Levelt, W. (1999). Models of word production. Trends in Cognitive Sciences, 3, 223-232.

Li, J., \& Schmitt, N. (2009). The acquisition of lexical phrases in academic writing: A longitudinal case study. Journal of Second Language Writing, 18, 85-102.

Littlemore, J. (2001). Metaphor as a source of misunderstanding for overseas students in academic lectures. Teaching in Higher Education, 6, 333-351.

Luce, P., Goldinger, S., Auer, E., \& Vitevitch, M. (2000). Phonetic priming, neighborhood activation, and PARSYN. Perception and Psychophysics, 62, 615-625.

McCarthy, M. (1998). Spoken Language and Applied Linguistics. Cambridge, UK: Cambridge University Press. 
Nadel, L., \& Hardt, O. (2011). Update on memory systems and processes. Neuropsychopharmacology, 36, 251-273.

Nelson, D., \& Garland, R. (1969). Amount and locus of stimulus-response overlap in paired associate acquisition. Journal of Experimental Psychology, 82, 297-300.

Nunberg, G., Sag, I., \& Wasow, T. (1994). Idioms. Language, 70, 491-538.

Paivio, A., Yuille, J., Madigan, S. (1968). Concreteness, imagery, and meaningfulness values for 925 nouns. Journal of Experimental Psychology, 76, 1-25.

Parkinson, D., (Ed.) (2006). Oxford Idioms Dictionary for Learners of English, $2^{\text {nd }}$ ed. Oxford, UK: Oxford University Press.

Philip, G. (2000). An idiomatic theme and variations. In C. Heffer, \& H. Sauntson (Eds.) Words in Context: A Tribute to John Sinclair on his Retirement (pp. 221-233). ELR Monograph 18. The University of Birmingham.

Philip, G. (2005). Discovering clines of variation: the location and analysis of noncanonical forms in general reference corpora. Presented at: Phraseology 2005: The many faces of Phraseology. An interdisciplinary conference, 13-15 October 2005, Louvain-la-Neuve, Belgium. Retrieved from http://amsacta.cib.unibo.it/1132/1/VariationInCorpus.pdf

Qi, Y., \& Ding, Y. (2011). Use of formulaic sequences in monologues of Chinese EFL learners. System, 39, 164-174.

R Core Team. (2015). R: A Language and Environment for Statistical Computing. R Foundation for Statistical Computing, Vienna, Austria. Retrieved from http://www.Rproject.org/ 
Rubin, D. (1995). Memory in Oral Traditions: The Cognitive Psychology of Epic, Ballads, and Counting-out Rhymes. Oxford, UK: Oxford University Press.

Storkel, H., \& Morrisette, M. (2002). The lexicon and phonology: Interactions in language acquisition. Language, Speech, and Hearing Services in Schools, 33, 24-37.

Tulving, E. (1972). Episodic and semantic memory. In E. Tulving \& W. Donaldson (Eds.), Organization of Memory (pp. 381-403). New York, US: Academic Press.

Tulving, E., \& Kroll, N. (1995). Novelty assessment in the brain and long-term memory encoding. Psychonomic Bulletin and Review, 2, 387-390.

Watkins, M., Watkins, O., \& Crowder, R. (1974). The modality effect in free and serial recall as a function of phonological similarity. Journal of Verbal Learning and Verbal Behavior, 13, 430-447.

Wilcox, R. (2005). Introduction to robust estimation and hypothesis testing, 2 nd edn. Waltham, MA: Academic Press.

Wilcox, R. (2012). Modern statistics for the social and behavioral sciences: A practical introduction. Boca Raton, FL: CRC Press.

Wuensch, K. (2009). An overview of power analysis. Greenville, NC: East Carolina University. Available at: core.ecu.edu/psyc/wuenschk/stathelp/PowerAnalysis_Overview.doc

Zyzik, E. (2011). Second language idiom learning: The effects of lexical knowledge and pedagogical sequencing. Language Teaching Research, 15, 413-433. 
Table 1 . The 26 targeted idioms

6

bring home the bacon

burn the midnight oil

cook the books

feel the pinch

get the show on the road

hit the spot

have bigger fish to fry

hold the purse strings

jump the gun

keep the wolf from the door

keep your eye on the ball

8

miss the mark

learn the ropes

9

press the panic button

paint the town red

10

pull the plug on

shoot the messenger

11

pull the wool over sb's eyes

sort out the sheep from the goats

12

set the scene for

stay the course

13

take the bull by the horns 
Table 2. Comparison of the targeted phonologically similar $(\mathrm{PhS})$ and nonphonologically similar (nonPhS) idioms

\begin{tabular}{|c|c|c|}
\hline & $P h S$ & nonPhS \\
\hline Number of words (Mean) & 4.31 & 4.23 \\
\hline Number of content words (Mean) ${ }^{\mathrm{a}}$ & 2.62 & 2.54 \\
\hline Number of syllables (Mean) & 4.77 & 4.46 \\
\hline Internal somebody / someone ${ }^{\mathrm{b}}$ & 1 & 0 \\
\hline Frequency of whole idiom (median) ${ }^{c}$ & 14 & 9 \\
\hline Total frequency of all content words (median) & 44,229 & 30,641 \\
\hline Frequency of words intended as responses in cued & 43,829 & 13,314 \\
\hline recall (median) ${ }^{\mathrm{d}}$ & & \\
\hline Mean imagery rating / Standard deviation & $5.84 / 1.24$ & $5.97 / 1.45$ \\
\hline
\end{tabular}

Notes.

a. Includes nouns, verbs, and adjectives.

b. This was counted as a noncontent word of one syllable.

c. As given by the online British National Corpus Simple Search facility: http:// http://www.natcorp.ox.ac.uk/using/index.xml?ID=simple

d. Lemma frequencies are as given by the Corpus of Contemporary American English (http://corpus.byu.edu/coca/) (Davies, 2008-2015) in September, 2013. 
Table 3. Scores of the AD (experimental) group $(n=26)$ for the $\mathrm{PhS}$ (phonologically similar) and the nonPhS idioms.

\begin{tabular}{|c|c|c|c|c|c|}
\hline \multicolumn{2}{|l|}{ SCORE SET } & \multirow[t]{3}{*}{ SUM / SD } & \multirow{3}{*}{$\begin{array}{l}\text { MEAN / } \\
\text { MEDIAN }\end{array}$} & \multirow{3}{*}{$\begin{array}{l}\text { NR OF } \\
\text { MAXIMUMS }\end{array}$} & \multirow{3}{*}{$\begin{array}{l}\text { INTER- } \\
\text { QUARTILE } \\
\text { RANGE }\end{array}$} \\
\hline & & & & & \\
\hline & & & & & \\
\hline PRETEST & $\mathrm{PhS}$ & $98 / 2.16$ & $3.77 / 3.00$ & 0 & $2.25-4.75$ \\
\hline $\mathrm{SUM}=200$ & nonPhS & $102 / 1.67$ & $3.92 / 4.00$ & 0 & $3.00-5.00$ \\
\hline IMMEDIATE & $\mathrm{PhS}$ & $272 / 1.86$ & $10.46 / 11.00$ & 5 & $9.25-11.75$ \\
\hline POSTTEST & nonPhS & $266 / 1.88$ & $10.23 / 10.50$ & 3 & $9.00-11.75$ \\
\hline $\mathrm{SUM}=538$ & & & & & \\
\hline DELAYED & $\mathrm{PhS}$ & $267 / 1.56$ & $10.27 / 10.50$ & 3 & $9.00-11.00$ \\
\hline POSTTEST & nonPhS & $239 / 2.00$ & $9.19 / 9.00$ & 0 & $8.00-11.00$ \\
\hline $\mathrm{SUM}=506$ & & & & & \\
\hline GAINS & $\mathrm{PhS}$ & $169 / 2.40$ & $6.50 / 6.50$ & 0 & $4.25-8.00$ \\
\hline $\mathrm{SUM}=306$ & nonPhS & $137 / 2.15$ & $5.27 / 5.00$ & 0 & $4.00-6.00$ \\
\hline GAIN DIFFEI & ENCES & $32 / 2.93$ & $1.23 / 1.00$ & 0 & $-1.00-3.00$ \\
\hline
\end{tabular}


Table 4. Scores of the noAD (comparison) group $(n=24)$ for the $\mathrm{PhS}$ and the nonPhS idioms.

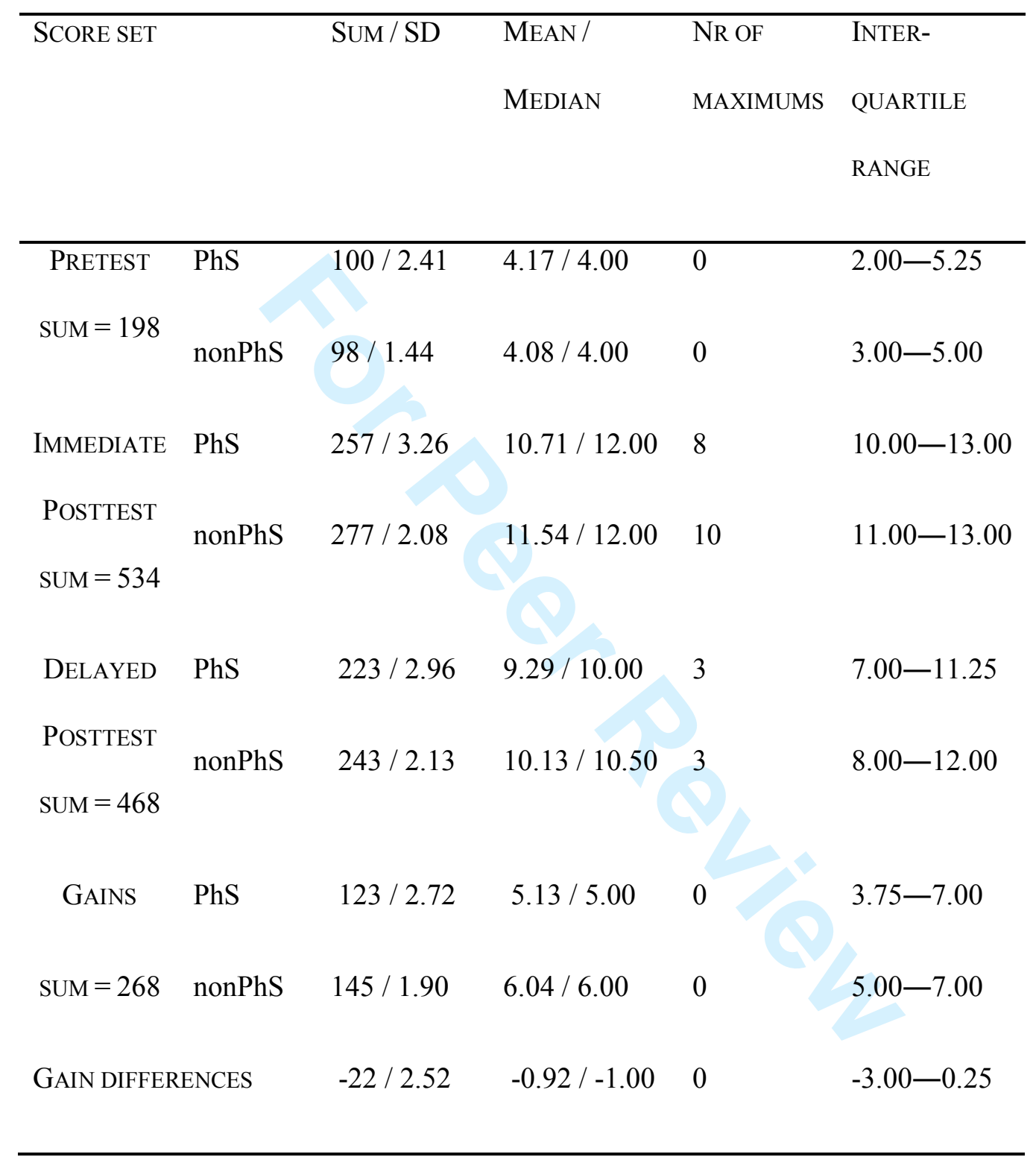


Figure 1. Gain profiles for the AD condition (top row) and the noAD condition (bottom row) and for the nonPhS idioms (left column) and the $\mathrm{PhS}$ idioms (right column), where Pre means raw pretest score and Post 1 means raw immediate posttest scores, and where $r$ gives the correlation between pretest and posttest scores. ${ }^{1}$

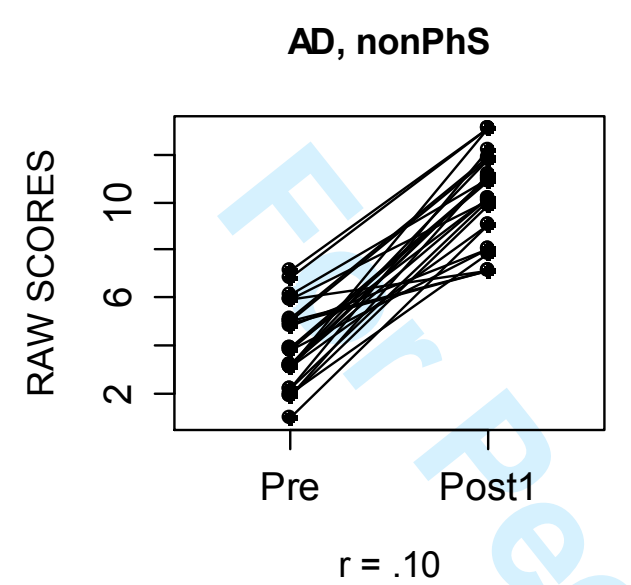

no $A D$, nonPhS

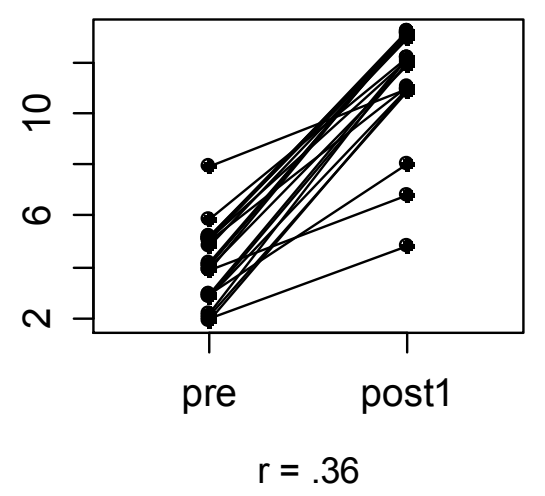

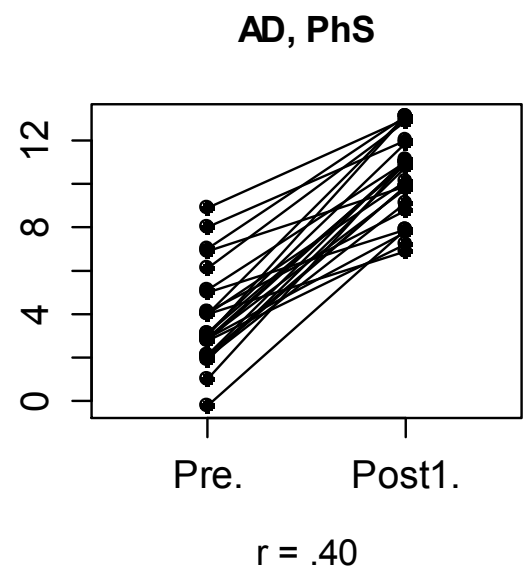

no AD, PhS

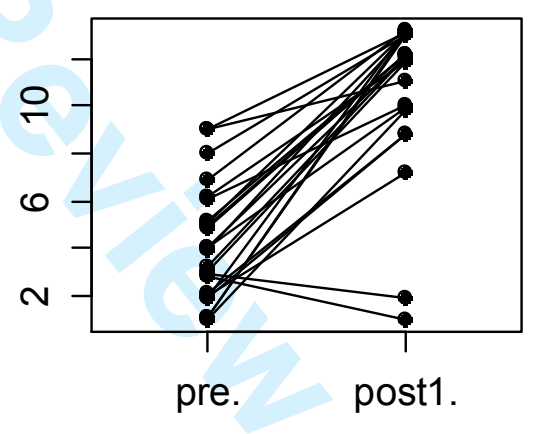

$r=.28$ 
Figure 2. Gain profiles for the AD condition (top row) and the noAD condition (bottom row) and for the nonPhS idioms (left column) and the $\mathrm{PhS}$ idioms (right column), where Pre means raw pretest score and Post 2 means raw delayed posttest scores.

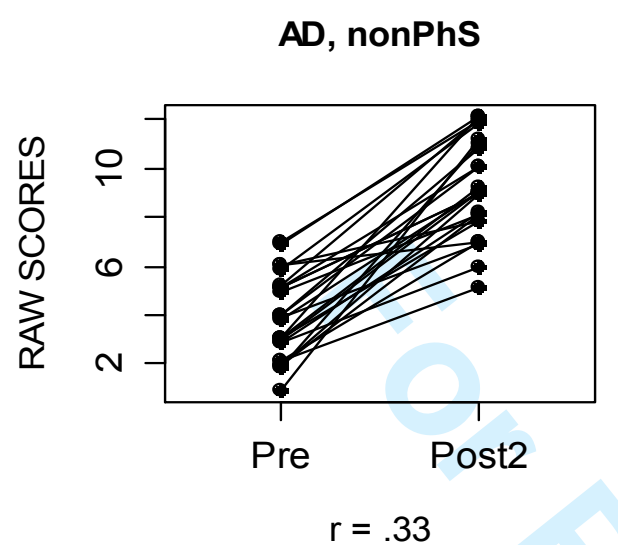

no AD, nonPhS

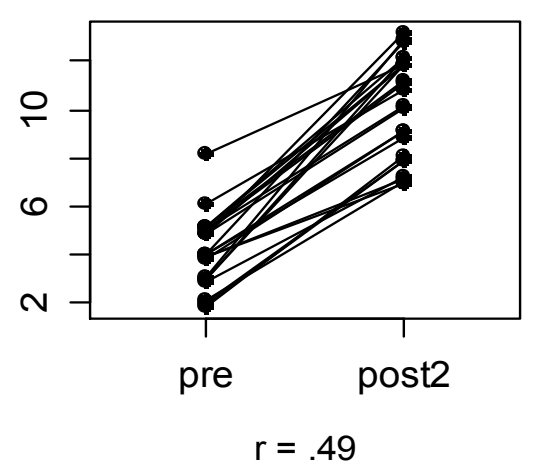

AD, PhS

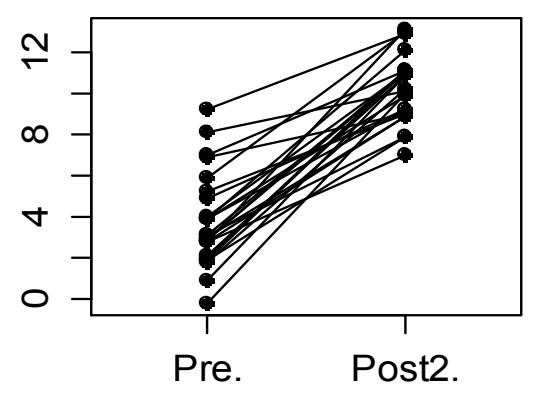

$r=.56$

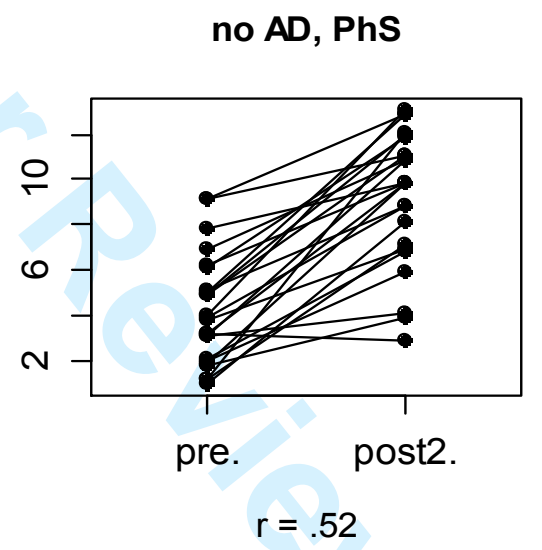

